\title{
Assessing Marriage and Family Therapy Graduate Students' Responses to Sexual Attraction in Therapy
}

\author{
Susan L. Williams ${ }^{1}$, Brenda L. Shook ${ }^{2}$, Jan S. Parker ${ }^{3}$ \\ ${ }^{1}$ Department of Psychology, National University, Stockton, CA, USA \\ ${ }^{2}$ Department of Psychology, National University, Sacramento, CA, USA \\ ${ }^{3}$ Department of Psychology, National University, San Diego, CA, USA \\ Email: swilliams@nu.edu,bshook@nu.edu,jparker@nu.edu
}

Received 29 January 2016; accepted 26 February 2016; published 29 February 2016

Copyright (C) 2016 by authors and Scientific Research Publishing Inc.

This work is licensed under the Creative Commons Attribution International License (CC BY). http://creativecommons.org/licenses/by/4.0/

(c) (i) 0pen Access

\section{Abstract}

Fifty-six full-time graduate Marriage and Family Therapy (MFT) counseling students responded to case scenarios involving a client's expression of feelings of love and sexual attraction toward the therapist. The scenarios differed by diagnosis of the client (adjustment disorder versus histrionic personality disorder) and students were asked about their comfort level in discussing how to manage this situation with either their supervisor, personal therapist or trusted colleague when the feelings of sexual attraction in therapy were mutual versus non-mutual. They also indicated their comfort level in discussing their client's feelings in the treatment, and continuing to treat the client versus referring the client out under these varying conditions. Overall students felt comfortable discussing a case with their supervisor, however students' comfort level was significantly higher when feelings of attraction were non-mutual. Students felt most comfortable talking with their own therapist relative to either their supervisor or a colleague about these cases. When feelings of sexual attraction were mutual, students were much less comfortable referring out the client diagnosed with a histrionic personality disorder compared to the client diagnosed with an adjustment disorder. Students reported feeling comfortable discussing a client's feelings of sexual attraction with the client regardless of type of diagnosis and whether those feelings were mutual or non-mutual. Students were more comfortable continuing therapy when feelings of sexual attraction were non-mutual than mutual. Implications for training regarding management of these issues are discussed.

\section{Keywords}

Sexual Attraction in Therapy, Erotic Transference, MFT Students, Counseling Trainees 


\section{Introduction}

Teaching counseling graduate students how to identify, address and respond to clients' expressions of love and sexual attraction in therapy, erotic transference and countertransference are some of the most difficult and neglected aspects of psychotherapist education and training (Bridges, 1994, 1998; Harris, 2001). This is highly problematic because as educators and supervisors of graduate trainees, we need to assist our students/trainees in learning about appropriate boundaries in the therapeutic relationship (Buhari, 2013; Ladson, Welton, \& Gillig, 2007; Perlman, 2009). Providing opportunities for trainees to talk about feelings of sexual attraction in therapy, whether mutual or non-mutual, is important and necessary for the best interest of both the client and the trainee. In so doing, supervisors can provide a safe place for exploration of sexual feelings, and/or erotic transference and countertransference. At the same time, they can also reinforce the notion that it is the trainee's responsibility to maintain the safety of their clients and never violate any boundaries which ultimately could lead to sexual misconduct in therapy.

Most of the literature discussing sexual attraction, erotic transference and countertransference in therapy stems from the psychoanalytic perspective, (Liitmaer, 2004; Mann, 1999; Ogden, 1999; Slavin, Rahmani, \& Pollock, 1998) which is highly informative but does not readily translate to the more diverse, short-term, behaviorally oriented training models that exist in many graduate counseling programs.

For the purpose of this paper, transference is defined as "the patient's perceptions and experiences of the therapist that are shaped by the patient's own psychological structures and past. These perceptions and experiences involve a carryover from the past, and a displacement onto the therapist of attitudes, feelings, and behaviors belonging rightfully in earlier significant relationships" and countertransference is defined as "the therapist's internal and external reactions to the patient based on the therapist's unresolved conflicts and vulnerabilities." (Gelso, Perez Rojas, \& Marmarosh, 2014: p. 123).

Many authors agree that aspects of sexual attraction are present in most client-therapist relationships (Bernsen, Tabachnick \& Pope, 1994; Hayes, 2014; Pope, Sonne, \& Greene, 2006; Pope, Sonne, \& Holroyd, 1993; Rodgers, 2011; Rouholamin, 2007; Sonne \& Jochai, 2014). Most students, however, report that their graduate program and/or clinical training did not address these issues adequately, if at all (Harris, 2001; Ladany et al., 1997; Pope, Keith-Spiegel, \& Tabachnick, 2006). The reasons for this are complex, and may include the clinical supervisor's, intern's or client's discomfort in talking about sexual attraction in therapy, the type of training program in which the trainee or intern is working, the type of client with whom the trainee is working, the length of treatment, the specific treatment modality, or other influencing factors.

Until more recently, it has been difficult to find material that discusses therapists' sexual feelings towards their clients, except in cases where the therapist acts out and crosses the ethical/legal boundary and becomes sexually involved with the client (Pope et al., 2006). Currently there is much discussion in educational programs about the ethical/legal issues related to those therapists who act out sexually with clients. However this is usually restricted to the prohibition against such activity and little discussion occurs about those therapists who do not act out sexually but do have sexual feelings for their clients and/or their clients have sexual feelings for them. "This suggests another possible myth: Good therapists (i.e., those who don't sexually exploit their patients), don't become sexually aroused during therapy sessions, don't vicariously enjoy the (sometimes) guilty pleasures of their patients' sexual experiences, and don't have sexual fantasies or dreams about their patients” (p. 99). Both supervisors and educators need to counteract this myth by being proactive in educating graduate counseling students that sexual feelings in therapy are normal and manageable as part of the therapeutic process (Pope et al., 1993). While trainees may feel shame, guilt, fear, confusion, discomfort, anger, and/or embarrassment discussing sexual attraction in therapy, (Bernsen et al., Ladany et al., 1997; Pope et al., 1993), it is crucial for supervisors and educators to address these issues to provide counseling students with effective ways of understanding and working through their feelings. Nickell, Hecker, Ray and Bercik (1995) found that when sexual behaviors or feelings are not specifically discussed or outlined as being either appropriate or inappropriate (according to the Code of Ethics), therapists reported little agreement regarding what may be helpful or harmful to clients when sexual attraction is anissue.

More recently, Gelso et al. (2014) have stated: "When examining love and sexuality in the therapeutic relationship it is deeply important for the therapist to seek understanding of his or her own and the patient's loving and sexual feelings, and to tease apart, as much as possible, the extent to which they are real relationship versus transference-countertransference based. The patient's loving and sexual feelings toward the therapist need to be 
explored and understood just as other feelings. Although it is crucial that the therapist seek understanding of his or her own loving and sexual feelings toward the patient, we express serious reservations about the therapeutic value of sharing these with the patient”. (p. 123).

Harris (2001) has recommended further research into the exploration of sexual attraction in therapy, especially with MFT graduate students as they have not been well represented in previous research, which has primarily been done with psychologists, social workers and trainees in both of these fields. Since MFT students treat couples and families in addition to individuals, the situations in which sexual attraction could develop are potentially much more complex and challenging.

In order to provide more information to the limited research regarding how MFT students respond to these issues, this pilot study explored a number of questions related to MFT graduate students' comfort level in dealing with feelings of sexual attraction in therapy. Specifically, we asked how comfortable they would feel talking about sexual attraction in therapy with their clinical supervisor, therapist or trusted colleague, and hypothesized that due to the confidential and non-judgmental nature of the therapeutic relationship, students would feel most comfortable discussing a case with their own therapist, followed by their clinical supervisor and lastly a trusted colleague. We also added a new dimension to this field of study by asking about students' comfort level in dealing with sexual attraction under differing diagnostic scenarios, (adjustment disorder vs histrionic personality disorder) and when feelings of sexual attraction between the student/trainee and client were mutual or non-mutual. We hypothesized that it might be more difficult dealing with feelings of sexual attraction when the client presents in a more sexually provocative way, (as is the case in the histrionic personality disorder scenario) and that it would be more difficult for trainees to discuss feelings of sexual attraction in supervision as well as with the client when the feelings were mutual versus non-mutual. As a follow-up, we explored how feelings of sexual attraction may affect how comfortable a student is in referring a client out to another therapist, or continuing on in therapy with the client, and how this may vary depending on the type of diagnosis and behavior of the client in the therapeutic relationship. We hypothesized that students would feel more comfortable referring out a client rather than continuing on in therapy when the feelings of sexual attraction were mutual, and would more likely refer out a client who exhibits sexually provocative behavior rather than continuing their treatment.

\section{Methods}

\subsection{Participants}

Participants were 56 full-time graduate students enrolled in a mandatory clinical practicum at the authors' institution. The sample included students from various campus locations in California who were at different stages of completing the six-month practicum. An informed consent form was signed by all participants.

\subsection{Materials}

The survey was developed by the authors of this study and contained three sections. The first section requested general demographic information such as age, sex, self-identified ethnicity (blank, fill in question), experience working in the mental health field, etc. The second section, central to the purpose of the survey, included four clinical vignettes pertaining to the diagnosis and treatment of sexual compulsivity and two pairs of case scenarios pertaining to sexual attraction/erotic transference in therapy. Data on sexual compulsivity has been previously published elsewhere (Shook, Parker, \& Williams, 2013) so here we include only the scenarios related to sexual attraction (see Appendix). The two pairs differed only with respect to the diagnosis of a client. The first part of each pair briefly described a case in which a client indicated sexual attraction for the therapist, and in the second part of each pair the sexual attraction between client and therapist was mutual. For both parts of each pair, students were asked to indicate how comfortable they would be discussing the sexual attraction with their clinical supervisor, a trusted colleague, and the client. One item inquired about how comfortable they would be referring the client out or continuing treatment. The third section of the survey asked questions about education and training relevant to sexual attraction.

\subsection{Procedure}

Subsequent to approval from the Institutional Review Board, instructors teaching ongoing sections of clinical practicum were contacted by telephone, provided information about the purpose of the survey and instructions 
for its administration. Instructors were provided via mail the surveys, informed consent forms, and a standard set of instructions that were to be read to students. To preserve the anonymity of respondents, completed surveys and signed consent forms were sealed in separate envelopes and returned to the authors.

\subsection{Parametric Statistical Analyses}

Within subjects F-Tests were used to compare the comfort ratings for each of the five hypotheses. Although parametric tests of significance have traditionally been reserved for use with quantitative data, many researchers now agree that the mean and parametric tests are sufficiently robust that they can be used to analyze Likert data with little measurement error (Boone \& Boone, 2012; Carifio \& Perla, 2007; Murray, 2013).

\section{Results}

\subsection{Demographics}

Details of participant characteristics have been reported elsewhere (Shook et al., 2013) and are briefly recounted here (Table 1). The majority of participants were female (82.14\%), heterosexual (92.86\%), and between 20 - 39 years of age (69.57\%). Most respondents were affiliated with a Christian religion (46.44\%) while another 25\% reported no religious affiliation. The remaining students (one or two in each category) reported a variety of affiliations such as Islam or Pagan. The majority of the sample self-reported as Caucasian (46.44\%), followed by Hispanic (16.07\%), African American (12.5\%), Asian (8.3\%), and mixed.

Table 1. Student demographic information as a percentage of the sample.

\begin{tabular}{|c|c|c|c|}
\hline Characteristic & Percent & Characteristic & Percent \\
\hline Sex & & Age & \\
\hline Female & 82.14 & $20-29$ & 41.05 \\
\hline Male & 16.07 & $30-39$ & 28.57 \\
\hline \multirow[t]{2}{*}{ Unknown } & 1.79 & $40-49$ & 17.86 \\
\hline & & $50-59$ & 7.14 \\
\hline Religious affiliation & & $60-69$ & 1.79 \\
\hline Agnostic & 5.36 & Unknown & 3.57 \\
\hline Christian & 51.8 & & \\
\hline Islam & 1.79 & Ethnicity & \\
\hline Pagan & 1.79 & African American & 12.50 \\
\hline None & 25.00 & Asian American & 8.93 \\
\hline Not Indicated & 3.57 & Caucasian & 46.44 \\
\hline \multirow[t]{3}{*}{ Spiritual } & 10.1 & Hispanic & 17.86 \\
\hline & & Mixed & 8.93 \\
\hline & & Unknown & 5.36 \\
\hline \multicolumn{4}{|l|}{ Sexual orientation } \\
\hline Heterosexual & 92.86 & Marital status & \\
\hline Bisexual & 5.36 & Married & 39.30 \\
\hline Gay & 0 & Single, never married & 30.36 \\
\hline Lesbian & 0 & Divorced & 25.00 \\
\hline \multirow[t]{3}{*}{ Unknown } & 1.79 & Domestic partnered & 1.79 \\
\hline & & Widowed & 1.79 \\
\hline & & Unknown & 1.79 \\
\hline
\end{tabular}




\subsection{Training and Education}

Table 2 illustrates the percent of students who indicated training and/or graduate education pertaining to issues of sexual attraction, erotic transference and countertransference in therapy. Over half (58.93\%) of the students indicated that they had formal education in their graduate training about working with sexual attraction, erotic transference and/or countertransference issues with clients. However, a large majority (76.79\%) reported that their clinical supervisors had never asked them about sexual attraction or erotic transference issues. The majority of students (82.14\%) reported that they had formal graduate training on how to discuss sexual issues with clients. A vast majority of students (83.93\%) reported that they had never worked with a client who expressed sexual feelings or attraction towards them.

\subsection{Hypothesis 1}

Feelings of sexual attraction may affect a student's comfort level in discussing a case with their clinical supervisor, and this effect may differ depending on client diagnosis. A two-way analysis of variance was used to test comfort levels among students based upon a scenario in which feelings of sexual attraction were non-mutual vs mutual and a client was diagnosed with either an adjustment disorder with mixed anxiety and depressed mood or histrionic personality disorder exhibiting sexually provocative behavior. Overall students felt comfortable discussing a case with their supervisor, however students' comfort level was significantly higher when feelings of attraction were non-mutual $\left(F(1,50)=16.48, p<0.001, \eta_{p}^{2}=0.29\right)$, than mutual (see Table 3 for cell means

Table 2. Percent of students reporting training, experience and education pertaining to sexual transference and/or countertransference.

\begin{tabular}{ccccc}
\hline Question Topic & Yes & No & NR/NA & Don't know \\
\hline Graduate education & 58.93 & 41.07 & -- & -- \\
Clinical supervisor & 21.4 & 76.79 & 1.79 & -- \\
Workshops/training & 17.86 & 78.57 & -- & 3.57 \\
Graduate training sexual issues & 82.14 & 17.86 & -- & -- \\
Client expressed attraction & 83.93 & 16.07 & -- & - \\
\hline
\end{tabular}

Table 3. Mean and standard deviation for each of the two scenarios (client diagnosis).

\begin{tabular}{|c|c|c|c|c|}
\hline & \multicolumn{2}{|c|}{ Non-mutual } & \multicolumn{2}{|c|}{ Mutual } \\
\hline & $\mathbf{M}$ & SD & $\mathbf{M}$ & SD \\
\hline \multicolumn{5}{|c|}{ Scenario 1 (adjustment disorder) } \\
\hline Supervisor & 4.76 & 0.79 & 3.83 & 1.37 \\
\hline Own therapist & 4.65 & 0.81 & 4.54 & 1.02 \\
\hline Refer out & 3.67 & 1.19 & 4.18 & 1.40 \\
\hline Discuss clients feelings & 4.20 & 1.03 & 4.12 & 1.11 \\
\hline Discuss with colleague & 2.81 & 1.48 & 2.78 & 1.53 \\
\hline Continue therapy & 1.68 & 1.29 & 1.50 & 1.20 \\
\hline \multicolumn{5}{|c|}{ Scenario 2 (histrionic personality disorder) } \\
\hline Supervisor & 4.70 & 0.77 & 4.26 & 1.21 \\
\hline Own therapist & 4.70 & 0.81 & 4.60 & 0.98 \\
\hline Refer out & 3.79 & 1.32 & 3.72 & 1.38 \\
\hline Discuss clients feelings & 4.32 & 0.77 & 4.04 & 1.20 \\
\hline Discuss with colleague & 2.95 & 1.59 & 2.86 & 1.50 \\
\hline Continue therapy & 1.84 & 1.41 & 1.76 & 1.30 \\
\hline
\end{tabular}

Note: Item "e” (discuss mutual feelings) from scenario 2 was not included in the analysis. 
and standard deviations). Students also reported significantly lower comfort levels as a function of client diagnosis $\left(F(1,50)=5.74, p=0.02, \eta_{p}^{2}=0.10\right)$, but this depended on whether feelings were non-mutual vs. mutual. There was a significant interaction between attraction and type of diagnosis $(F(1,50)=11.27, p=0.002$, $\eta_{p}^{2}=0.18$ ). When sexual feelings were mutual, students were much less comfortable discussing the case with their supervisor when the client was diagnosed with an adjustment disorder than with a histrionic personality disorder, but when feelings were non-mutual there was little difference between comfort ratings as a function of diagnosis (Figure 1).

\subsection{Hypothesis 2}

Due to the confidential nature of the therapeutic relationship, students would be expected to feel more comfortable discussing a case with their own therapist than with their clinical supervisor or a trusted colleague. However, comfort levels could vary depending on the type of client diagnosis (adjustment disorder vs histrionic personality disorder) and whether feelings of sexual attraction between student/trainee and client were mutual or nonmutual. A 3-way repeated measures ANOVA was used to test the main effects and interactions between attraction, client diagnosis, and type of relationship. Table 3 shows the mean and standard deviations for each condition. The main effect of attraction was significant $\left(F(1,35)=5.82, p=0.02, \eta_{p}^{2}=0.143\right)$. Students reported feeling more comfortable discussing a case when feelings of sexual attraction were non-mutual than mutual. The main effect of relationship was significant; $F(2,70)=30.15, p<0.001, \eta_{p}^{2}=0.46$. The pattern of overall cell means (collapsing across attraction and diagnosis) indicated that students felt more comfortable talking with their own therapist relative to either their supervisor or a colleague. The pairwise comparisons for the main effect of relationship using Fisher's LSD test showed a significant difference between supervisor and therapist ( $p$ $=0.05)$, supervisor and colleague $(p<0.001)$, and therapist and colleague $(p<0.001)$. However, there was a significant interaction between attraction and relationship $\left(F(2,70)=5.25, p=0.008, \eta_{p}^{2}=0.13\right)$. As can be seen in Figure 2 students reported feeling the most uncomfortable discussing a case with a colleague relative to their supervisor or therapist regardless of whether or not feelings of sexual attraction were mutual. Students felt the most comfortable discussing a case with their clinical supervisor, but much less so when feelings of sexual attraction were mutual. Feelings of sexual attraction did not affect comfort levels for discussing a case with their therapist.

The main effect for diagnosis $\left(F(1,35)=2.05, p=0.16, \eta_{p}^{2}=0.06\right)$, the interaction between attraction and diagnosis $\left(F(1,35)=0.396, p=0.53, \eta_{p}^{2}=0.01\right)$, the interaction between diagnosis and relationship $(F(2,70)$ $\left.=0.91, p=0.41, \eta_{p}^{2}=0.03\right)$, and the 3-way interaction $\left(F(2,70)=1.68, p=0.19, \eta_{p}^{2}=0.05\right)$,) were all nonsignificant.

\subsection{Hypothesis 3}

Feelings of sexual attraction may affect how comfortable a student is in referring a client out to another therapist, and this may vary depending on the type of diagnosis and behavior of the client in the therapeutic relationship.

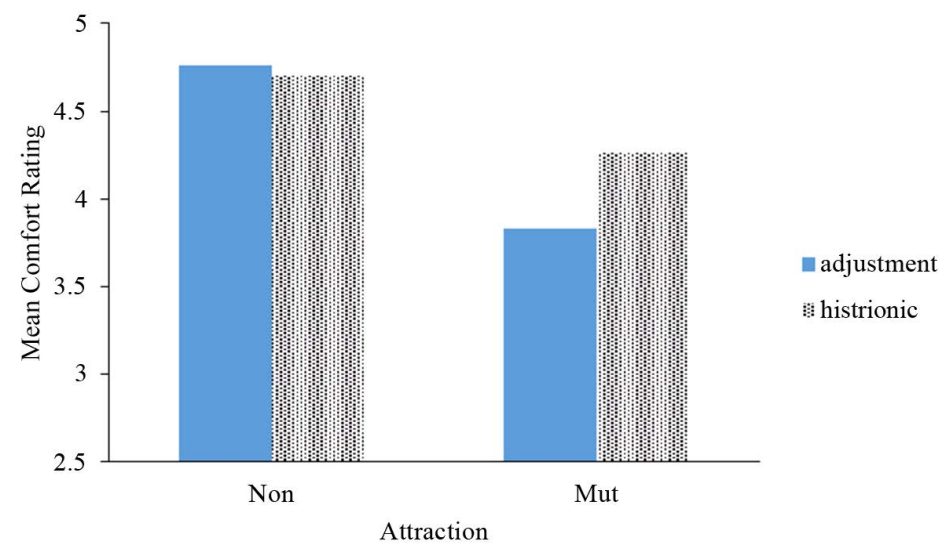

Figure 1. Mean comfort level discussing case with a supervisor as a function of attraction and client diagnosis. 


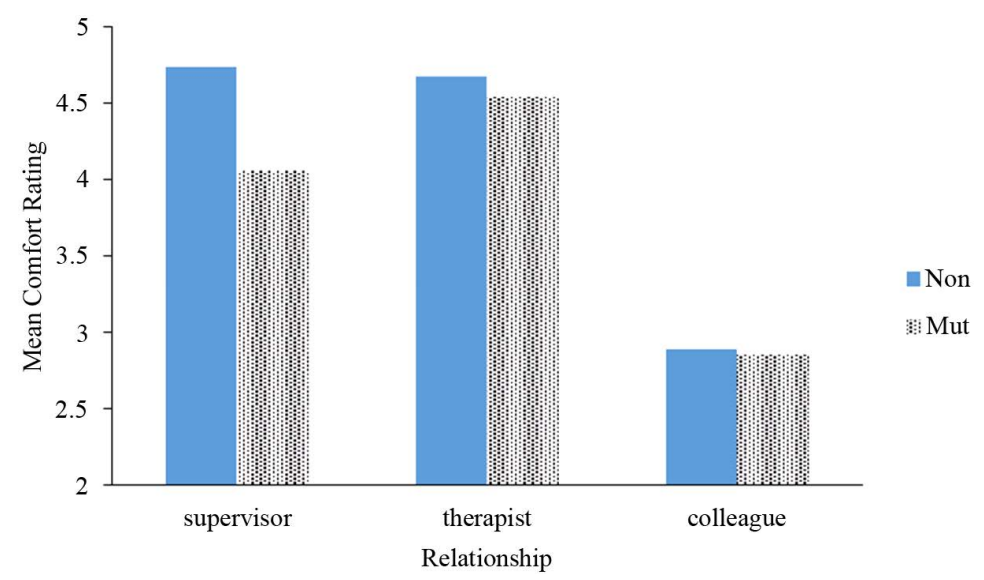

Figure 2. Comfort level discussing a case with their supervisor, therapist, or colleague when feelings of sexual attraction were non-mutual vs. mutual.

A 2-way repeated measures ANOVA was used to test comfort levels in referring a client out when feelings of sexual attraction were non-mutual vs. mutual and the client was diagnosed with either an adjustment disorder (no sexually provocative behavior exhibited) or a histrionic personality disorder (sexually provocative behavior exhibited). The main effect of attraction was significant $\left(F(1,38)=3.94, p=0.05, \eta_{p}^{2}=0.09\right)$, as was the attraction x scenario interaction $\left(F(1,38)=3.75, p=0.06 . \eta_{p}^{2}=0.09\right)$. As can be seen in Figure 3 , students were more comfortable referring a client out to another therapist when feelings of sexual attraction were mutual than non-mutual. When feelings of sexual attraction were mutual, students were much less comfortable referring out the client diagnosed with a histrionic personality disorder who displayed sexually provocative behaviors compared to the client diagnosed with an adjustment disorder and did not exhibit provocative behaviors. This pattern, though much smaller, was reversed when feelings of sexual attraction between student/trainee and client was non-mutual. The main effect of diagnosis was not significant $\left(F(1,38)=0.40, p=0.52, \eta_{p}^{2}=0.01\right)$.

\subsection{Hypothesis 4}

A client's feelings of sexual attraction toward the student/trainee may affect the student's level of comfort in discussing those feelings with the client, and this may vary depending upon the type of diagnosis. There was no significant main effect for attraction $\left(F(1,46)=1.96, p=0.17, \eta_{p}^{2}=0.04\right)$, diagnosis $(F(1,46)=0.10, p=$ 0.75 , partial $\eta^{2}=0.002$ ), or the attraction $\mathrm{x}$ diagnosis interaction, $\left.F(1,46)=0.80, p=0.38, \eta_{p}^{2}=0.02\right)$. Students reported feeling comfortable discussing a client's feelings of sexual attraction with the client regardless of whether those feelings were non-mutual (client attracted to student) or mutual, and their comfort level was not affected by the type of client diagnosis.

\subsection{Hypothesis 5}

Feelings of sexual attraction within a therapeutic relationship may affect how comfortable a student is in continuing therapy with a client, and this may be exacerbated if a client exhibits sexually provocative behavior. A two-way repeated measures ANOVA was used to examine the effects of sexual attraction and client diagnosis on students' comfort with continuing therapy. There was a significant main effect for attraction, $F(1,35)=3.25$, $p=0.08, \eta_{p}^{2}=0.09$. Students were more comfortable continuing therapy when feelings of sexual attraction were non-mutual than mutual (Figure 4). The main effect of diagnosis was not significant $(F(1,35)=2.41, p=$ $\left.0.13, \eta_{p}^{2}=0.06\right)$, nor was the attraction $\mathrm{x}$ diagnosis interaction, $F(1,35)=0.30, p=0.59, \quad \eta_{p}^{2}=0.01$.

\section{Discussion}

As we hypothesized, students were most comfortable talking about sexual attraction with their therapist, followed by their supervisor and least comfortable talking with a colleague, regardless of whether or not the feelings were mutual or non-mutual. This makes sense in that the therapeutic relationship is completely confidential and non-evaluative in nature. Students were also comfortable talking with their supervisor about sexual attraction 


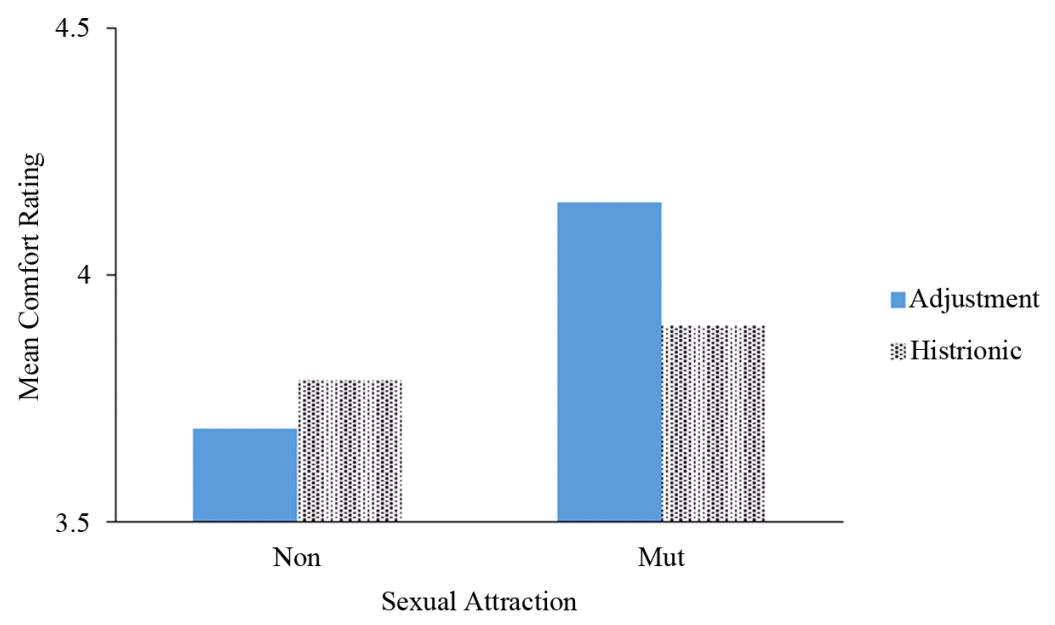

Figure 3. Mean comfort level in referring a client out as a function of feelings of sexual attraction and type of client diagnosis.

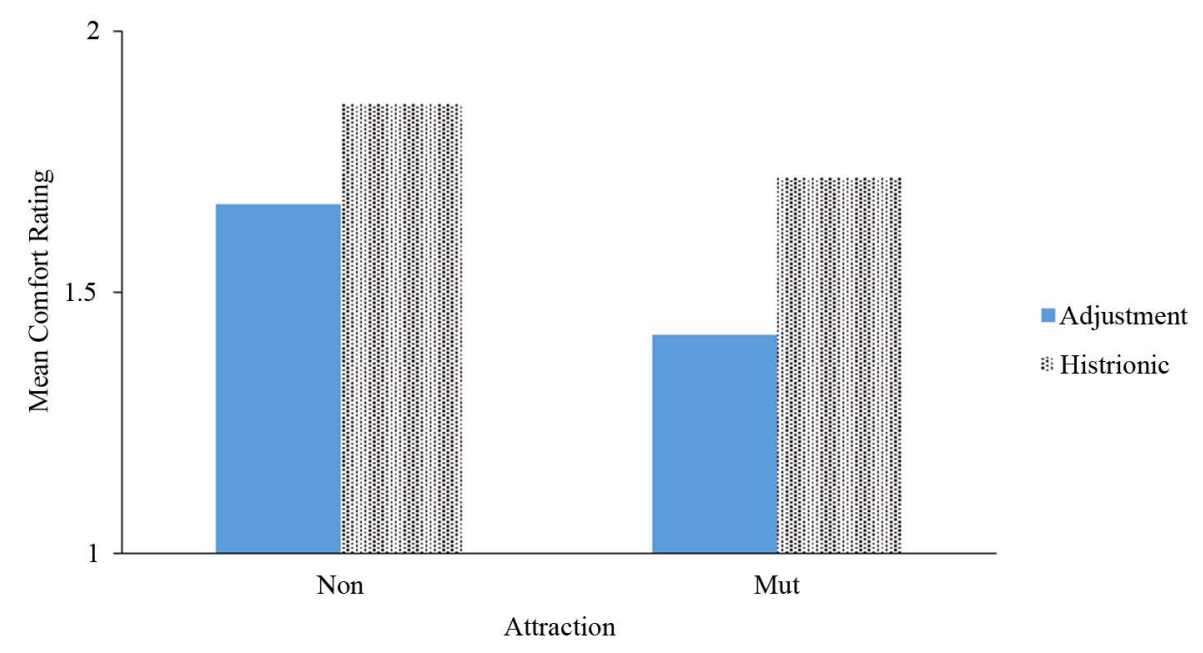

Figure 4. Mean comfort rating for continuing therapy as a function of attraction and client diagnosis.

but more so when it was non-mutual than mutual. This suggests that there may be some concern regarding how they are viewed by their supervisor when being more vulnerable by admitting to mutual sexual attraction towards their clients. Our students were least comfortable talking about sexual attraction in therapy with colleagues. While we do not know the specific reason for this finding, in previous research (Harris, 2001) it was noted that trainees were hesitant to talk about these issues with colleagues for fear of being seen as unethical in their behavior or concern that the colleague would possibly report them for an ethical violation.

As we hypothesized, our students were more comfortable referring a client out to another therapist when the feelings of sexual attraction were mutual rather than non-mutual. Referring clients out in these cases ensures that no boundaries will be violated by the trainee, however it is certainly not the sole way to manage this situation. An unexpected finding was that when feelings of sexual attraction were mutual, students reported feeling less comfortable referring out the client who exhibited sexually provocative behavior and a histrionic personality diagnosis and more comfortable referring out a higher functioning client with an adjustment disorder with depressed and anxious mood. Perhaps there was concern that the histrionic client might take the referral as more of a rejection and a potential abandonment of them since their behavior had been more sexually provocative and feelings of attraction were mutual. A qualitative follow-up study could ask students for their rationale in these decisions. In general, however, type of diagnosis did not have a significant impact on the students' decision making. 
Contrary to our hypothesis, students indicated they would be comfortable talking about feelings of sexual attraction with their clients regardless of whether these feelings were mutual or non-mutual, and there was no difference in this finding by client diagnosis. This is an interesting finding in light of the fact that a vast majority of our students (83.93\%) reported that they had never worked with a client who expressed sexual feelings or attraction towards them. They may believe in theory they would be comfortable in this situation because $58.93 \%$ indicated they had received graduate education in working with erotic transference and countertransference, and 82.14\% noted they had had formal education in their graduate program regarding talking about sexual issues with clients. These are much higher figures than have been noted in previous graduate samples. It still remains to be seen how these results would actually translate to real experiences with clients.

As we predicted, our students reported being more comfortable continuing in therapy when the feelings of sexual attraction were non-mutual than mutual. This was true regardless of type of diagnosis.

\subsection{Implications for Training}

The issue of sexual attraction in therapy clearly needs more attention in both MFT graduate education and supervision. Within graduate programs, it can be addressed across a wide range of courses such as Ethics, Practicum, Counseling Paradigms, Couples Therapy, Family Therapy, Child and Adolescent Therapy, and Human Sexuality. Having an on-going discussion about this issue across the curriculum would help to normalize this phenomenon and allow for a more open and candid dialogue regarding how to effectively manage these feelings in treatment This can be done in a variety of formats including watching DVDs of experienced clinicians re-enacting therapy sessions where sexual attraction is an issue, utilizing detailed case scenarios in class for both small group discussion and general class discourse, reading recent research in this area for class discussion and debate, doing student role-plays, and bringing in guest speakers on this topic. In addition, it is vitally important for instructors to model effective ways to manage feelings of sexual attraction in therapy which can be done by sharing their own past clinical experiences with sexual attraction in therapy in both mutual and non-mutual conditions as well as doing role-plays as the therapist for the class to observe their specific interventions in action.

Clinical supervisors need to be very proactive in bringing up the issue of sexual attraction in therapy with their supervisees. In so doing, they model that it is a safe place to discuss the topic and that it is a common phenomenon experienced by most therapists. Previous qualitative research with a small group of pre-doctoral psychology trainees indicated that about half of them were hesitant to bring this issue up in supervision for a variety of reasons, including believing that these feelings weren't important enough to discuss or relevant to supervision, having negative feelings about their supervisor and doubting their ability to manage the topic competently, being worried that their supervisor wouldn't be supportive or that they might be insensitive or disrespectful and probe too much (Ladany et al., 1997). In this study, most trainees who did disclose to their supervisors found them to be helpful, validating and supportive, but there were also negative instances noted where the supervisor was distant, competitive or sexually harassed the therapist. Clearly, this is an issue that supervisors need more training on (through attendance at continuing education seminars, consultation with colleagues, keeping updated with the research in this area, attending professional conferences, etc.) to ensure that they can provide a safe, wellinformed, comfortable and respectful setting for these issues to be explored in depth.

\subsection{Limitations of the Study}

One limitation of this study is that we utilized a convenience sample of our MFT graduate students enrolled in practicum classes to complete our surveys, so the results cannot be readily generalized to other populations. A replication study with a representative sample of MFT students is warranted for further exploration of these results. Another limitation of the study is that a vast majority of our students (83.93\%) reported that they had never worked with a client who expressed sexual feelings or attraction towards them. Therefore, their responses to the survey were more theoretical in nature rather than stemming from actual experiences of this phenomenon.

\subsection{Directions for Future Research}

The vast majority of the research done in this area has been survey research. This does not allow for a more in-depth exploration of how therapists actually deal with sexual attraction in treatment and what they need from training and supervision to be more comfortable and competent at managing these issues. It would be very informative to conduct qualitative research with MFT students looking at various scenarios where the sexual at- 
traction occurs in individual, couples and family therapy to expand the scope of this discussion. Additionally, it would be valuable to conduct qualitative interviews with MFT trainees who have actually experienced sexual attraction in therapy to learn more about how that developed, what steps they took to manage it, and how helpful those steps were in treating their clients. They could also be asked for recommendations regarding other interventions that might have been of greater assistance to them in dealing with the sexual feelings while maintaining appropriate boundaries. Through further exploration into these issues, researchers will be able to identify successful training strategies for both educators and supervisors to utilize when working with students to manage feelings of sexual attraction in therapy in a professional, ethical and respectful manner.

\section{References}

Boone, H. N., \& Boone, D. A. (2012). Analyzing Likert Data. Journal of Extension, 50, Article No.: 2 TOT2. http://wiki.biologyscholars.org/@api/deki/files/2002/=Likert_Scale_Analysis.pdf

Bridges, N. (1994). Meaning and Management of Attraction: Neglected Areas of Psychotherapy Training and Practice. Psychotherapy: Theory, Research and Practice, Training, 31, 424-433. http://dx.doi.org/10.1037/0033-3204.31.3.424

Bridges, N. (1998). Teaching Psychiatric Trainees to Respond to Sexual and Loving Feelings: The Supervisory Challenge. Journal of Psychotherapy Practice and Research, 7, 217-226.

Buhari, 'B. (2013). Therapeutic Relationships and Professional Boundaries. Ife Psychologia, 21, 162-168.

Carifio, J., \& Perla, R. J. (2007). Ten Common Misunderstandings, Misconceptions, Persistent Myths and Urban Legends about Likert Scales and Likert Response Formats and Their Antidotes. Journal of Social Sciences, 3, 106-116. http://dx.doi.org/10.3844/jssp.2007.106.116

Gelso, C. J., Perez Rojas, A. E., \& Marmarosh, C. (2014) Love and Sexuality in the Therapeutic Relationship. Journal of Clinical Psychology: In Session, 70, 123-134. http://dx.doi.org/10.1002/jclp.22064

Harris, S. (2001). Teaching Family Therapists about Sexual Attraction in Therapy. Journal of Martial and Family Therapy, 27, 123-128. http://dx.doi.org/10.1111/j.1752-0606.2001.tb01145.x

Hayes, J. A. (2014). “Well I Got a Few of My Own”: Therapists’ Reactions to Attraction, Sex, and Love in Psychotherapy. Journal of Clinical Psychology: In Session, 70, 119-122. http://dx.doi.org/10.1002/jclp.22063

Ladany, N., O’Brien, K. M., Hill, C. E., Melincoff, D. S., Knox, S., \& Peterson, D. A. (1997). Sexual Attraction toward Clients, Use of Supervision and Prior Training: A Qualitative Study of Pre-Doctoral Psychology Interns. Journal of Counseling Psychology, 44, 413-424. http://dx.doi.org/10.1002/jclp.22063

Ladson, D., Welton, R., \& Gillig, P. M. (2007). Recognizing and Managing Erotic and Eroticized Transference. Psychiatry, 4, 47-50.

Liitmaer, R. M. (2004). The Place of Erotic Transference and Countertransference in Clinical Practice. Journal of the American Academy of Psychoanalysis and Dynamic Psychiatry, 32, 483-498. http://dx.doi.org/10.1521/jaap.32.3.483.44775

Mann, D. (Ed.) (1999). Erotic Transference and Countertransference: Clinical Practice in Psychotherapy. New York: Routledge. http://dx.doi.org/10.4324/9780203360736

Murray, J. (2013). Likert Data: What to Use, Parametric or Non-Parametric? International Journal of Business and Social Sciences, 4, 258-264. www.ijbssnet.com

Nickell, N. J., Hecker, L. L., Ray, R. E., \& Bercik, J. (1995). Marriage and Family Therapists’ Sexual Attraction to Clients: An Exploration Study. American Journal of Family Therapy, 23, 315-327. http://dx.doi.org/10.1080/01926189508251362

Ogden, J. K. (1999). Love and Sex in 45 Minutes: Transference Love as Self- and Mutual Regulation. Psychoanalytic Psychology, 16, 588-604. http://dx.doi.org/10.1037/0736-9735.16.4.588

Perlman, S. D. (2009). Falling into Sexuality: Sexual Boundary Violations in Psychotherapy. Psychoanalytic Review, 96, 917-941. http://dx.doi.org/10.1521/prev.2009.96.6.917

Pope, K. S., Sonne, J. L., \& Greene, B. (2006). What Therapists Don't Talk about and Why: Understanding Taboos That Hurt Us and Our Clients (2nd ed.). Washington DC: American Psychological Association. http://dx.doi.org/10.1037/11413-000

Pope, K. S., Sonne, J. L., \& Holroyd, J. (1993). Sexual Feelings in Psychotherapy: Explorations for Therapists and Therapists-in-Training. Washington DC: American Psychological Association. http://dx.doi.org/10.1037/10124-000

Pope, K., Keith-Spiegel, P., \& Tabachnick, B. (2006). Sexual Attraction to Clients: The Human Therapist and the (Sometimes) Inhuman Training System. Training and Education in Professional Psychology, S, 96-111.

http://dx.doi.org/10.1037/1931-3918.S.2.96

Rodgers, N. M. (2011). Intimate Boundaries: Therapists' Perception and Experience of Erotic Transference within the Therapeutic Relationship. Counseling and Psychotherapy Research, 11, 266-274. 
http://dx.doi.org/10.1080/14733145.2011.557437

Rouholamin, C. (2007). The "Frame” as a Container for the Erotic Transference-A Case Study. Psychodynamic Practice: Individuals, Groups and Organizations, 13, 181-196. http://dx.doi.org/10.1080/14753630701273082

Slavin, J. H., Rahmani, M. A., \& Pollock, L. (1998). Reality and Danger in Psychoanalytic Treatment. Psychoanalytic Quarterly, 67, 191-217.

Sonne, J. L., \& Jochai, D. (2014). The "Vicissitudes of Love” between Therapist and Patient: A Review of the Research on Romantic and Sexual Feelings, Thoughts, and Behaviors in Psychotherapy. Journal of Clinical Psychology: In Session, 70, 182-195. http://dx.doi.org/10.1002/jclp.22069 


\section{Appendix Sexual Attraction Vignettes}

SCENARIO \#1: You are treating a 25 year old single female for an adjustment disorder with mixed anxiety and depressed mood. She has a good job and is generally very high functioning. She does not have a personality disorder. Two months into the treatment, she tells you that she is falling in love with you and has strong feelings of sexual attraction toward you. You do not feel any sexual attraction toward your client.

1. Would you discuss this situation with your clinical supervisor?

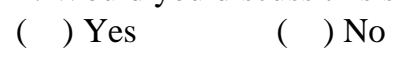

2. If you answered "Yes" to question \#1, please rate your comfort level in discussing this situation with your clinical supervisor:

Very Uncomfortable Somewhat Uncomfortable Neutral Somewhat Comfortable Very Comfortable $\begin{array}{lllll}1 & 2 & 3 & 4 & 5\end{array}$

3. If you answered "No" to question \#1, how would you handle this situation?

a) refer your client to another therapist because of her feelings of sexual attraction to you

b) discuss it with your client in terms of her transference feelings and assure her that no sexual contact will occur between the two of you.

c) discuss it with a trusted colleague instead of your clinical supervisor

d) continue therapy without focusing on the sexual attraction, since you know it won't be acted upon in any way.

Looking at Scenario \#1 again, suppose you did feel sexually attracted to your client as well but were aware that you could not act upon these feelings.

4. Would you discuss this situation with your clinical supervisor?

( ) Yes ( ) No

5. If you answered Yes to the question \#4, please rate your comfort level in discussing this situation with your clinical supervisor:

Very Uncomfortable Somewhat Uncomfortable Neutral Somewhat Comfortable Very Comfortable

$\begin{array}{lllll}1 & 2 & 3 & 4\end{array}$

6. If you said No to question \#4, how would you handle this situation?

a) refer your client to another therapist because of the mutual feelings of sexual attraction

b) discuss it with your client in terms of her transference feelings and assure her that no sexual contact will occur between the two of you.

c) Discuss it with your client in terms of your feelings of mutual attraction towards each other, and assure her that no sexual contact will occur between the two of you.

d) discuss it with a trusted colleague instead of your clinical supervisor

e) continue therapy without focusing on the sexual attraction, since you know it won't be acted upon in any way.

SCENARIO \# 2. You are working with a 22 year old single female who comes to see you following a relationship break-up. She is very distraught and about this loss and very emotionally expressive and dramatic in her clinical presentation. She likes being the center of attention with her friends and is somewhat sexually provocative in therapy. You have diagnosed her with a Histrionic Personality Disorder. Two months into the treatment, she tells you that she is falling in love with you and has strong feelings of sexual attraction toward you. You do not feel any sexual attraction toward you client.

7. Would you discuss this situation with your clinical supervisor?

( ) Yes ( ) No

8. If you answered "Yes" to question \#7, please rate your comfort level in discussing this situation with your clinical supervisor:

Very Uncomfortable Somewhat Uncomfortable Neutral Somewhat Comfortable Very Comfortable

$\begin{array}{lllll}1 & 2 & 3 & 4 & 5\end{array}$

9. If you answered "No" to question \#7, how would you handle this situation? 
a) refer your client to another therapist because of her feelings of sexual attraction to you

b) discuss it with your client in terms of her transference feelings and assure her that no sexual contact will occur between the two of you.

c) discuss it with a trusted colleague instead of your clinical supervisor

d) continue therapy without focusing on the sexual attraction, since you know it won't be acted upon in any way.

In the above scenario, how would you handle the situation if you did feel sexually attracted to your client as well but were aware that you could not act upon these feelings?

(Circle as many as apply)

a) discuss it with your clinical supervisor

b) discuss it with your therapist

c) refer your client to another therapist because of the mutual feelings of sexual attraction

d) discuss it with your client in terms of her transference feelings and assure her that no sexual contact will occur between the two of you.

e) Discuss it with your client in terms of your feelings of mutual attraction towards each other, and assure her that no sexual contact will occur between the two of you.

f) discuss it with a trusted colleague instead of your clinical supervisor

g) continue therapy without focusing on the sexual attraction, since you know it won't be acted upon in any way. 